\title{
Acaricidal Activity of DHEMH, Derived from Patchouli Oil, against House Dust Mite, Dermatophagoides farinae
}

\author{
Hai-Qiang Wu, ${ }^{*, a}$ Li Li, ${ }^{a, \#}$ Jing Li, ${ }^{a}$ Zhen-Dan He, ${ }^{b}$ Zhi-Gang Liu, ${ }^{b}$ Qing-Qian Zeng, ${ }^{c}$ and \\ Yu-Sheng Wang \\ ${ }^{a}$ College of Life Sciences, Shenzhen University; ${ }^{b}$ College of Medicine, Shenzhen University; Shenzhen 518060, \\ China: and ${ }^{c}$ Guangdong Research Institute of Traditional Chinese Medicines; Guangzhou 510000, China. \\ Received June 11, 2011; accepted November 8, 2011
}

This study characterized the acaricidal activity of constituents of patchouli oil extracted from (Pogostemon cablin (Blanco) BENTH) against the house dust mite, Dermatophagoides farinae. A new compound, 2-(1,3-dihydroxy-but-2-enylidene)-6-methyl-3-oxo-heptanoic acid (DHEMH), was isolated from patchouli oil and characterized by ${ }^{1} \mathrm{H}-\mathrm{NMR},{ }^{13} \mathrm{C}-\mathrm{NMR}$, LC-MS and elemental analysis (EA). This active component was identified as the hydrolysate of pogostone. Fifteen other constituents found in patchouli oil were also identified by GC-MS, including patchouli alcohol and pogostone. $L_{50}$ studies carried out over $24 \mathrm{~h}$ using contact toxicity tests identified DHEMH as the most toxic compound to $D$. farinae $\left(2.04 \mu \mathrm{g} / \mathrm{cm}^{2}\right)$, followed by patchouli oil $\left(6.11 \mu \mathrm{g} / \mathrm{cm}^{2}\right)$, benzyl benzoate (BP) $\left(9.31 \mu \mathrm{g} / \mathrm{cm}^{2}\right)$ and dibutyl phthalate (DBP) $\left(58.52 \mu \mathrm{g} / \mathrm{cm}^{2}\right)$. In vapor phase toxicity tests, all of these compounds were more effective in closed than open containers, indicating that the most efficient mode of delivery for these compounds is the vapor phase. These results indicate that DHEMH and patchouli oil merit further study as potential agents for the control of D. farinae. mode

Key words natural acaricide; Dermatophagoides farinae; Pogostemon cablin (Blanco); identification; action

The increase of allergic diseases, such as asthma, allergic rhinitis and atopic dermatitis, can be related to changes in lifestyle, including a rise in the number of apartment households, space heating, tighter windows and fitted carpets. House dust mites, such as Dermatophagoides farinae (Hughes) and Dermatophagoides pteronyssinus (Trouessart), are a major cause of these diseases. ${ }^{1-3)}$ A reduction in the number of house dust mites in a living environment and/or a reduction in exposure time to house dust mites have been shown to cause a reduction in house dust mite-associated allergy symptoms in sensitive persons. ${ }^{4,5}$ As a result, various attempts have been implemented to control mite populations. Among the different approaches, the use of chemicals, such as $\gamma$-benzene hexachloride $(\gamma$-BHC), benzyl benzoate (BP), $N, N$-diethyl- $m$-toluamide (DEET) and dibutyl phthalate (DBP), has been shown to be effective. $^{6-8)}$ However, the repeated use of chemicals has undesirable effects on non-target organisms, raises environmental and human health concerns, and can result in the development of acaricide resistance due to the mite's high reproductive potential and short life cycle. ${ }^{6,9,10)}$ Hence, the discovery of plantderived acaricides that are selective, biodegradable and safer for non-target organisms and the environment is desirable.

Many studies have been conducted to identify natural acaricides derived from medicinal plants. ${ }^{10-13)}$ It has been demonstrated that preparations from clove, eucalyptus, caraway and fennel are much more effective than the chemicals currently used against $D$. farinae and/or D. pteronyssinus. ${ }^{11,13-17)}$

The medicinal properties of Pogostemon cablin (Blanco) BENTH are well-known in China. ${ }^{18)}$ In agricultural applications, P. cablin exhibited high insecticidal activity against Preris rapae L., Plutella xylostella L., Delias aglaia L., and Homona coffearia Nietner. ${ }^{19,20)}$ It was also found that the essential oils of $P$. cablin can inhibit intestinal bacteria, dozens of skin bacteria and a variety of plant pathogens. ${ }^{21-23)}$ No studies have been carried out to examine the potential of $P$. cablin for the management of house dust mites. Therefore, this study was conducted to identify constituents of patchouli oil extracted from the acrial part of $P$. cablin that exhibit acaricidal activity against adult $D$. farinae.

\section{Experimental}

Chemicals Petroleum ether II (AR) was purchased from Guangzhou Chemical Reagent Factory I. Two chemical insecticides used in this study (BP (98\%) and DBP (98\%)) and were purchased from China National Medicines Corporation Ltd. All other chemicals were of reagent grade and commercially available.

Stock Culture of House Dust Mite D. farinae house dust mites were maintained in our laboratory for five years without exposure to any known acaricides. They were reared on a finely ground mixture of dust, dried yeast and bean cake $(1: 1: 0.5$ by weight) in complete darkness. Stock jars were kept in an incubator at an average temperature of $25 \pm 2{ }^{\circ} \mathrm{C}$ and relative humidity of $80 \pm 5 \%$.

Preparation of Patchouli Oil Pogostemon cablin (Blanco) Benth $(0.5 \mathrm{~kg})$ was purchased from Shenzhen Accordance Pharmaceutical Co., Ltd. (China). The sample was washed three times with $200 \mathrm{~mL}$ of distilled water and dried in an oven at $40^{\circ} \mathrm{C}$ for $3 \mathrm{~d}$ and then finely powdered with a pulverizer (DFY-500g, Wenling, China). The patchouli oil was extracted with petroleum ether II $(400 \mathrm{~mL})$ twice by Soxhlet extraction and filtered. The combined filtrate was dried using anhydrous $\mathrm{Na}_{2} \mathrm{SO}_{4}$ and concentrated to dryness under a vacuum at $50^{\circ} \mathrm{C}$ using a rotary evaporator (RV06-ML 1-B, IKA, Germany).

Preparation and Identification of 2-(1,3-Dihydroxy-but2-enylidene)-6-methyl-3-oxo-heptanoic Acid (DHEMH) Further separation of the patchouli oil was carried out as follows: patchouli oil ( $1 \mathrm{~mL}$ dissolved in $5 \mathrm{~mL}$ ether) was extracted with $2 \mathrm{~mL} \mathrm{NaOH}(1 \mathrm{~mol} / \mathrm{L})$ five times. ${ }^{24)}$ The $\mathrm{pH}$ of the pooled alkaline aliquots was adjusted to $\mathrm{pH} 2$ with $\mathrm{HCl}(1 \mathrm{~mol} / \mathrm{L})$ and the pooled aliquot was further extracted 
with $10 \mathrm{~mL}$ ether twice. The pooled ether aliquots were dried using anhydrous $\mathrm{Na}_{2} \mathrm{SO}_{4}$ and concentrated to dryness under a vacuum at $50^{\circ} \mathrm{C}$. The resulting extracted oil was separated on a silica gel column using petroleum ether/ethyl acetate (94:6 by volume) as the eluent. Column fractions were analyzed by thin-layer chromatography (TLC) (silica gel $60 \mathrm{~F}_{254}$ ) and fractions with similar streaking patterns on the TLC plates were pooled. The solid potent active ingredient, DHEMH, was isolated after removing the solvent under a vacuum. Yellow, needle-shaped crystals were obtained by further re-crystallization from diluted ether.

The structure of the isolated compound was determined by spectroscopic analyses. ${ }^{1} \mathrm{H}$ - and ${ }^{13} \mathrm{C}-\mathrm{NMR}$ spectra were recorded with a DRX-400 NMR spectrometer (BRUKER, Germany) at $400 \mathrm{MHz}$ using tetramethylsilane as an internal standard. Chemical shifts are given in $\delta$ (ppm). Mass spectra were obtained using a LCQ DECA XP liquid chromatographymass spectrometry (Thermo, U.S.A.). Elemental analysis (EA) spectra were obtained with a Vario EL CHNS elemental analyzer (Elementar, Germany).

Analysis of Patchouli Oil by Gas Chromatography-Mass Spectrometry (GC-MS) Patchouli oil was analyzed on a gas chromatograph-mass spectrometer (Voyager, Finnigan, U.S.A.). The GC column was a $30 \mathrm{~m} \times 0.25 \mathrm{~mm}$ capillary column coated with a $0.25 \mu \mathrm{m}$ film of $5 \%$ phenyl methyl siloxane. The GC conditions were as follows: injector temperature, $220^{\circ} \mathrm{C}$; column temperature, isothermal at $120^{\circ} \mathrm{C}$ for $3 \mathrm{~min}$, to $220^{\circ} \mathrm{C}$ at $3^{\circ} \mathrm{C} \mathrm{min}^{-1}$, followed by a hold at $220^{\circ} \mathrm{C}$ for $5 \mathrm{~min}$; ion source temperature, $200^{\circ} \mathrm{C}$; split injection $(50: 1)$; helium carrier gas $\left(1 \mathrm{~mL} \mathrm{~min}^{-1}\right)$. The GC column effluent was introduced directly into the MS. The MS was operated in electron-impact (EI) mode, and the sector mass analyzer was set to scan from 20 to $400 \mathrm{amu}$. Compounds were identified by retention time comparison, and mass spectra were obtained with authentic standards analyzed on the GC-MS system. When an authentic standard was not available, identification was carried out by comparison of mass spectra from a mass spectra library (The Wiley Registry of Mass Spectral Data, 6th ed.).

Contact Toxicity Bioassay A filter paper contact toxicity bioassay ${ }^{15)}$ was used to evaluate the toxicity of isolated DHEMH, patchouli oil, BP and DBP. In the filter paper contact toxicity bioassay, doses are determined by the mass of samples adsorbed on the filter paper after drying $\left(\mu \mathrm{g} / \mathrm{cm}^{2}\right)$. Test materials $(2 \mathrm{mg} / \mathrm{mL})$ were dissolved in $200 \mu \mathrm{L}$ of petroleum ether and applied to Whatman filter paper $(5.6 \mathrm{~cm}$ diameter). Ten doses $(0.3,0.6,1.2,2.4,4.8,9.5,19.1,38.1,76.2$, $152.4 \mu \mathrm{g} / \mathrm{cm}^{2}$ ) were used. Control filter paper received equal volumes of petroleum ether. After drying in a fume hood $\left(20^{\circ} \mathrm{C}\right)$ for $2 \mathrm{~min}$, each filter paper preparation was separately placed on the bottom of a Petri dish $(5.5 \mathrm{~cm}$ diameter $\times 1.2 \mathrm{~cm})$ coated with a layer of Vaseline on the inside wall. Groups of 55-65 adult mites (female and male) were introduced into Petri dishes containing a piece of cotton $(5 \mathrm{~mm} \times 5 \mathrm{~mm})$ impregnated with $2 \mathrm{~mL}$ of distilled water. Each Petri dish was then covered with a lid and kept in an incubator at an average temperature of $25 \pm 2{ }^{\circ} \mathrm{C}$ and relative humidity of $80 \pm 5 \%$. Mortalities were determined $24 \mathrm{~h}$ post-treatment under a binocular microscope $(20 \times)$. Mites were deemed dead if their legs did not move when they were prodded with a fine pin 14. All treatments were performed in triplicate.

To evaluate the potency of these materials against $D$. fari- nae, mortalities were also determined at $0.5,1,1.5,2$ and $2.5 \mathrm{~h}$ post-treatment as described above.

Vapour Phase Toxicity Bioassay The susceptibility of adult $D$. farinae to the test compounds in the vapor phase was investigated according to the method of Kwon and Ahn. ${ }^{14)}$ A single dose above which mortality of the test material was $100 \%$ in the contact toxicity assay was used. The test compounds prepared in petroleum ether were applied to Whatman filter paper $(5.6 \mathrm{~cm}$ diameter $)$ at the selected doses. Each treated filter paper was separately attached to the top of a Petri dish lid. Mites were introduced into the bottom of a Petri dish and each Petri dish was covered with a lid with treated filter paper (tightly closed container, method A or $95 \%$ closed container, method B) to investigate the potential vapor phase toxicity of the extracts. Mortalities were determined at $24 \mathrm{~h}$ post-treatment. All other conditions were the same as described above for the contact toxicity assay.

Analysis of Bioassay Results Data were corrected for the control mortality using Abbott's formula. ${ }^{25)} \mathrm{LD}_{50}$ values were calculated by probit analysis (Statistical Analysis System Institute, 2004) which is a classical comprehensive procedure that has been previously described..$^{13,15,17)}$ Acaricidal activity was considered significantly different when 95\% confidence limit levels of the $\mathrm{LD}_{50}$ values failed to overlap. Mortality percentages were determined and transformed to arcsine square root values for analysis of variance (ANOVA). The Scheffé's test was used to test for significant differences among the test compounds and acaricides. A paired $t$-test was used to test for significant differences between the two treatment methods. Means ( \pm S.E.M.) of untransformed data are reported.

\section{Results}

Identification of Patchouli Oil Components A novel active component was isolated from patchouli oil and was identified as DHEMH by spectroscopic analysis (Fig. 1). The identification was made based on the following evidence: $\mathrm{C}_{12} \mathrm{H}_{18} \mathrm{O}_{5}$; LC-MS, $m / z$ (\% relative intensity) $\mathrm{M}^{+} 242.32$ (52), 189.26 (100); EA (\%), C 59.51, H 7.43, O 33.06; ${ }^{1} \mathrm{H}-\mathrm{NMR}\left(\mathrm{CDCl}_{3}\right.$, $500 \mathrm{HMz}) \delta: 5.90(1 \mathrm{H}, \mathrm{s}), 3.044(2 \mathrm{H}, \mathrm{t}, J=7.6 \mathrm{~Hz}), 2.238(3 \mathrm{H}$, s), $1.600(2 \mathrm{H}, \mathrm{q}, J=6.8 \mathrm{~Hz}), 1.523(1 \mathrm{H}, \mathrm{m}, J=6.8 \mathrm{~Hz}), 0.914$ $(3 \mathrm{H}, \mathrm{d}), 0.897(3 \mathrm{H}, \mathrm{d}) ;{ }^{13} \mathrm{C}-\mathrm{NMR}\left(\mathrm{CDCl}_{3}, 500 \mathrm{MHz}\right) \delta: 208.3 \mathrm{~s}$, $181.3 \mathrm{~s}, 168.8 \mathrm{~s}, 160.9 \mathrm{~s}, 101.5 \mathrm{~s}, 99.5 \mathrm{~s}, 39.7 \mathrm{~s}, 32.9 \mathrm{~s}, 27.8 \mathrm{~s}$, $22.4 \mathrm{~s}, 22.4 \mathrm{~s}, 20.6 \mathrm{~s}$.

The substances identified by GC-MS in patchouli oil are presented in Table 1. GC-MS analysis led to the identification of 15 compounds including alcohols, lactones, aliphatics, ketones, aliphatic acids and epoxides. Most of the identified components are volatile. Patchouli alcohol (32.96\%) and pogostone $(25.58 \%)$ were the main constituents of patchouli oil.

Contact Toxicity with Treated Filter Paper The acari-

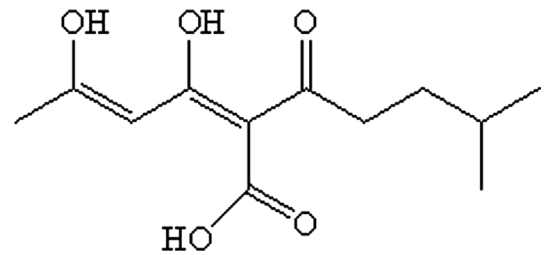

Fig. 1. Structure of the Novel Compound (DHEMH) Isolated from Patchouli Oil 
Table 1. Patchouli Oil Constituents Identified by GC-MS

\begin{tabular}{|c|c|c|c|c|c|}
\hline No. & Constituent & Formula & M.W. & $\begin{array}{l}\text { Retention time } \\
\quad(\min )\end{array}$ & Content $(\%)$ \\
\hline 1 & Cinnamaldehyde & $\mathrm{C}_{9} \mathrm{H}_{8} \mathrm{O}$ & 132 & 35.97 & 0.24 \\
\hline 2 & $\beta$-Patchoulene & $\mathrm{C}_{15} \mathrm{H}_{24}$ & 204 & 41.72 & 1.09 \\
\hline 3 & Thujopsene & $\mathrm{C}_{15} \mathrm{H}_{24}$ & 204 & 43.68 & 0.39 \\
\hline 4 & $\begin{array}{l}\text { 1a,2,3,4,6,7,7a,7b-Octahydro-1,1,4,7-tetrameth- } \\
\text { yl-1H-cyclopropa[e]azulene }\end{array}$ & $\mathrm{C}_{15} \mathrm{H}_{24}$ & 204 & 46.15 & 6.09 \\
\hline 5 & $\alpha$-Bulnesene & $\mathrm{C}_{15} \mathrm{H}_{24}$ & 204 & 46.84 & 3.81 \\
\hline 6 & Patchoulene & $\mathrm{C}_{15} \mathrm{H}_{24}$ & 204 & 47.16 & 0.79 \\
\hline 7 & Eudesma-4(14),11-diene & $\mathrm{C}_{15} \mathrm{H}_{24}$ & 204 & 48.49 & 0.33 \\
\hline 8 & $\begin{array}{l}\text { 2,3,3-Trimethyl-2-((E)-3-methylbuta-1,3-dienyl)- } \\
\text { cyclohexanone }\end{array}$ & $\mathrm{C}_{14} \mathrm{H}_{22} \mathrm{O}$ & 206 & 53.85 & 1.87 \\
\hline 9 & Caryophyllene oxide & $\mathrm{C}_{15} \mathrm{H}_{24} \mathrm{O}$ & 220 & 54.32 & 0.68 \\
\hline 10 & $\gamma$-Gurjunene & $\mathrm{C}_{15} \mathrm{H}_{24}$ & 204 & 59.83 & 11.56 \\
\hline 11 & Patchouli alcohol & $\mathrm{C}_{15} \mathrm{H}_{26} \mathrm{O}$ & 222 & 60.39 & 32.96 \\
\hline 12 & Pogostone & $\mathrm{C}_{12} \mathrm{H}_{16} \mathrm{O}_{4}$ & 224 & 63.63 & 25.58 \\
\hline 13 & $n$-Hexadecanoic acid & $\mathrm{C}_{16} \mathrm{H}_{32} \mathrm{O}_{2}$ & 256 & 69.27 & 6.22 \\
\hline 14 & Linoleic acid & $\mathrm{C}_{18} \mathrm{H}_{32} \mathrm{O}_{2}$ & 280 & 71.23 & 2.86 \\
\hline 15 & Octadecanoic acid & $\mathrm{C}_{18} \mathrm{H}_{36} \mathrm{O}_{2}$ & 284 & 71.41 & 1.18 \\
\hline
\end{tabular}

Table 2. Toxicity of DHEMH, Patchouli Oil, BP and DBP to Adult D. farinae Using a Filter Paper Contact Toxicity Bioassay (24h Exposure) $)^{a)}$

\begin{tabular}{ccccc}
\hline \hline Compounds & Initial mite number & Slope \pm S.E. & $\mathrm{LD}_{50}\left(\mu \mathrm{g} / \mathrm{cm}^{2}\right)$ & $95 \% \mathrm{CL}$ \\
\hline DHEMH & 329 & $6.43 \pm 0.53$ & 2.04 & $1.42-2.67$ \\
Patchouli oil & 331 & $3.28 \pm 0.16$ & 6.11 & $5.59-6.63$ \\
BP $^{b)}$ & 332 & $3.56 \pm 0.21$ & 9.31 & $7.43-12.16$ \\
DBP $^{b)}$ & 330 & $4.55 \pm 0.31$ & 58.52 & $52.32-65.19$ \\
\hline
\end{tabular}

a) There was no mortality in the untreated controls. $b$ ) Reference chemicals with known acaricidal activity.

Table 3. Toxicity of DHEMH, Patchouli Oil, BP and DBP for Adult D. farinae Using a Filter Paper Contact Toxicity Bioassay at Varying Doses and Exposure Times (h) ${ }^{a)}$

\begin{tabular}{|c|c|c|c|c|c|c|c|}
\hline \multirow{2}{*}{ Compounds } & \multirow{2}{*}{$\begin{array}{l}\text { Initial mite } \\
\text { number }\end{array}$} & \multirow{2}{*}{$\begin{array}{c}\operatorname{Dose}^{b)} \\
\left(\mu \mathrm{g} / \mathrm{cm}^{2}\right)\end{array}$} & \multicolumn{5}{|c|}{ Mortality, \% (mean \pm S.E.) } \\
\hline & & & $0.5 \mathrm{~h}$ & $1 \mathrm{~h}$ & $1.5 \mathrm{~h}$ & $2.0 \mathrm{~h}$ & $2.5 \mathrm{~h}$ \\
\hline DHEMH & 960 & 9.75 & $3.67 \pm 2.51^{c}$ & $16.31 \pm 3.33^{c)}$ & $42.56 \pm 2.66^{c}$ & $69.55 \pm 2.00^{c}$ & $100.00 \pm 0.00$ \\
\hline Patchouli oil & 992 & 19.51 & $20.62 \pm 6.13^{c)}$ & $87.87 \pm 6.18^{c)}$ & $97.29 \pm 2.43^{c)}$ & $100.00 \pm 0.00$ & $100.00 \pm 0.00$ \\
\hline $\mathrm{BP}$ & 978 & 36.56 & $14.84 \pm 3.74^{c)}$ & $70.06 \pm 1.27^{c)}$ & $85.43 \pm 5.79^{c)}$ & $90.79 \pm 4.80^{c)}$ & $94.59 \pm 4.82^{c)}$ \\
\hline DBP & 986 & 141.43 & $0.00 \pm 0.00$ & $3.83 \pm 1.63^{c)}$ & $5.07 \pm 1.42^{c)}$ & $7.52 \pm 1.10^{c)}$ & $13.24 \pm 2.11^{c)}$ \\
\hline
\end{tabular}
a)
-test.

cidal activity of DHEMH against $D$. farinae adults was examined by direct contact and compared with that of patchouli oil, BP and DBP. It was shown that the toxicity of DHEMH was greater than that of patchouli oil. At a dose of $7.32 \mu \mathrm{g} / \mathrm{cm}^{2}$, the mortality of DHEMH was $100 \%$ while that of patchouli oil was only $52 \%$. On the basis of $24 \mathrm{~h} \mathrm{LD}_{50}$ values, DHEMH was the most toxic compound $\left(2.04 \mu \mathrm{g} / \mathrm{cm}^{2}\right)$, and was more effective than patchouli oil $\left(6.11 \mu \mathrm{g} / \mathrm{cm}^{2}\right)$, BP $\left(9.31 \mu \mathrm{g} / \mathrm{cm}^{2}\right)$ and especially DBP $\left(58.52 \mu \mathrm{g} / \mathrm{cm}^{2}\right)$ (Table 2$)$.

On the basis of this toxicity, the potency of the test compounds against $D$. farinae adults was evaluated $0.5,1,1.5$, 2 and $2.5 \mathrm{~h}$ after treatment (Table 3). The mortality with DHEMH was much lower than that with patchouli oil and BP (16, 88, $70 \%$, respectively) after $1 \mathrm{~h}$ of exposure. However, after $2.5 \mathrm{~h}$ of exposure, the mortalities of DHEMH and patchouli oil were both $100 \%$, which were higher than that of BP and DBP. Mortality was not detected in the untreated control experiments.
Route of Acaricidal Action The fumigant toxicities of DHEMH, patchouli oil, BP and DBP to adult $D$. farinae were investigated using a vapor phase toxicity bioassay in two formats. After $24 \mathrm{~h}$ exposure to the different compounds at different doses, there was a significant difference in lethal activity between exposure in a closed container (method A), which resulted in $100 \%$ mortality for DHEMH and patchouli oil, and exposure in an open container (method B), which resulted in $16 \%$ and $10 \%$ mortality for DHEMH and patchouli oil, respectively (Table 4). The fumigant activity of DHEMH and patchouli oil was comparable with that of BP in the closed container but less effective than in the open container. There was no mortality in the DBP control exposure both in method $\mathrm{A}$ and in method $\mathrm{B}$ or in the untreated control experiments.

\section{Discussion}

Some plant preparations are known to possess acaricidal activity against house dust mites and have been suggested as a 
Table 4. Fumigant Activity of DHEMH, Patchouli Oil, BP and DBP against Adult D. farinae Using Vapor Phase Toxicity Bioassays (Methods A and B) at Various Doses for $24 \mathrm{~h}$ Exposure ${ }^{a)}$

\begin{tabular}{|c|c|c|c|c|}
\hline Compounds & Initial mite number & $\operatorname{Dose}^{b)}\left(\mu \mathrm{g} / \mathrm{cm}^{2}\right)$ & Method $^{c)}$ & Mortality, \% (土S.E.) \\
\hline \multirow[t]{2}{*}{ DHEMH } & 185 & 9.75 & A & $100.00 \pm 0.00$ \\
\hline & 183 & 9.75 & B & $15.86 \pm 3.30^{d)}$ \\
\hline \multirow[t]{2}{*}{ Patchouli oil } & 192 & 15.84 & A & $100.00 \pm 0.00$ \\
\hline & 189 & 15.84 & $\mathrm{~B}$ & $10.20 \pm 1.45^{d)}$ \\
\hline \multirow[t]{2}{*}{$\mathrm{BP}$} & 190 & 93 & $\mathrm{~A}$ & $100.00 \pm 0.00$ \\
\hline & 188 & 93 & B & $42.15 \pm 2.87^{d)}$ \\
\hline \multirow[t]{2}{*}{ DBP } & 195 & 141.43 & $\mathrm{~A}$ & $0.00 \pm 0.00$ \\
\hline & 187 & 141.43 & B & $0.00 \pm 0.00$ \\
\hline
\end{tabular}

a) There was no mortality in the untreated controls. b) Doses with $100 \%$ mortality at this and higher doses in the $24 \mathrm{~h}$ contact bioassay. $c$ ) A, closed container; B, open container. $d$ ) Significant at $p<0.05$, according to a paired $t$-test.

promising alternative for mite control products to the chemical acaricides that are currently used. ${ }^{11-18)}$ Most of the naturally occurring substances with acaricidal activity are essential oils.

In the present study, the acaricidal constituents of patchouli oil extracted from $P$. cablin were isolated and identified. 15 compounds, including patchouli alcohol and pogostone, were characterized. Most of the isolated compounds are volatile as reported previously. ${ }^{21,26-29)}$

The separation method described by Kong ${ }^{24)}$ was used here to efficiently and rapidly isolate the main active constituent of patchouli oil, pogostone. ${ }^{19)}$ The first two steps of the method, alkaline liquid extraction from ether solution and ether extraction from acidic liquid, remove most of the minor components based on their different solubility in different solutions and liquid phases. One potent active component was isolated after silica gel column chromatography and yellow, needle-shaped crystals of the compound were obtained by recrystallization. Spectroscopic analysis identified this active component as DHEMH. Kong ${ }^{24)}$ reported isolating a different compound, pogostone. Pogostone is a ketone containing lactone and therefore unstable in alkaline and acidic conditions. ${ }^{30-34)}$ An openring hydrolysis reaction resulted in the formation of DHEMH from pogostone during the extraction and separation (Fig. 2).

The acaricidal activity of DHEMH against adult $D$. farinae was tested systematically here and compared with that of patchouli oil, BP and DBP. Responses varied according to the compound identity and dose. Based on $24 \mathrm{~h} \mathrm{LD}_{50}$ values, DHEMH was the most toxic material, followed by patchouli oil, BP and DBP. An hour after exposure, the potency of DHEMH was lower than that of patchouli oil and BP. However, the mortality with DHEMH was $100 \%$ after $2.5 \mathrm{~h}$ exposure and the toxicity of DHEMH against adult $D$. farinae was much greater than that of the other compounds. Compounds derived from plant essential oils with reported acaricidal activity include alcohols, aldehydes, ketones, alkanes, terpenooids and monoterpenoids. ${ }^{11-16)}$ Although the precise modes of action and structure-activity relationships of these acaricidal compounds require further clarification, $\mathrm{C}=\mathrm{C}$ bonds and hydroxyl groups are the main functional groups. Furthermore, the acaricidal activity of the compounds may also be attributed, in part, to their lipophicity and high vapor pressures. Based on the results shown here, the strong acaricidal activity of DHEMH may be attributed to the conjugated enol structure that contains both a $\mathrm{C}=\mathrm{C}$ bond and hydroxyl group. Moreover, the activity of DHEMH could also be partially attributed to its lipophilicity. Our results indicate that

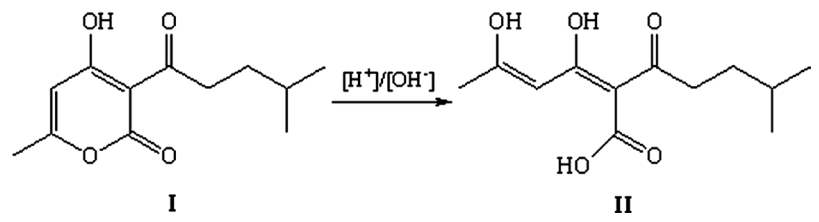

Fig. 2. Generation of DHEMH (II) from the Hydrolysis of Pogostone (I)

DHEMH merits further study as a potential dust mite control agent, although further research is required to determine the exact mechanism of action.

Essential oils and medicinal plants, such as clove bud oil ${ }^{11)}$ and Cnidium rhizome preparation, ${ }^{14)}$ exhibit fumigant activity against $D$. farinae. In the present research, the fumigant activity of DHEMH was examined using a vapor phase toxicity bioassay. DHEMH, patchouli oil and BP were much more effective in closed containers (method A) than in open containers (method B). These results suggest that the compounds are primarily delivered in the vapor phase, and that the mechanism of their toxicities depend on the mite's respiratory system. While DBP showed some acaricidal activity in the contact toxicity assay, it showed no significant fumigant action. Elucidation of the precise modes of action of these compounds requires further study. Spray formulations are widely accepted by the public and are convenient to use. Therefore, a spray containing both DHEMH and patchouli oil would be useful to reduce the number of $D$. farinae in living environments, thereby reducing house dust mite associated allergy symptoms in sensitive persons.

In conclusion, a novel compound, DHEMH, was isolated from patchouli oil and characterized spectroscopically. Both DHEMH and patchouli oil exhibited much stronger acaricidal activity against adult $D$. farinae than two chemical acaricides, $\mathrm{BP}$ and DBP, currently in use. These results suggest that DHEMH and patchouli oil may be useful as effective, simple and environmentally friendly fumigant alternatives to chemical acaricides.

Acknowledgements This study was supported by Grants from the Planned Science and Technology Project of Shenzhen (No. JSA200903190973A).

\section{References}

1) Arlian L. G., Immunol. Allergy Clin. North Am., 9, 339-356 (1989).

2) Sporik R., Chapman M. D., Platts-Mills T. A., Clin. Exp. Allergy, 
22, 897-906 (1992).

3) Lee H. S., Planta Med., 70, 279-281 (2004).

4) Semic Jusufagic A., Simpson A., Woodcock A., Curr. Allergy Asthma Rep., 6, 521-526 (2006).

5) de Vries M. P., van den Bemt L., Aretz K., Thoonen B. P., Muris J. W., Kester A. D., Cloosterman S., van Schayck C. P., Br. J. Gen. Pract., 57, 184-190 (2007).

6) Pollart S. M., Chapman M. D., Platts-Mills T. A., Prim. Care, 14, 591-603 (1987).

7) Kim H. K., Kim J. R., Ahn Y. J., J. Stored Prod. Res., 40, 55-63 (2004).

8) Collins D. A., J. Stored Prod. Res., 42, 395-426 (2006).

9) Szlendak E., Conyers C., Muggleton J., Thind B. B., Exp. Appl. Acarol., 24, 45-54 (2000).

10) Dekeyser M. A., Pest Manag. Sci., 61, 103-110 (2005).

11) Kim E. H., Kim H. K., Ahn Y. J., J. Agric. Food Chem., 51, 885889 (2003)

12) Rezk H. A., Gadelhak G. G., Phytophaga, XIV, 667-673 (2004).

13) Jeong E. Y., Kim M. G., Lee H. S., Pest Manag. Sci., 65, 327-331 (2009).

14) Kwon J. H., Ahn Y. J., J. Agric. Food Chem., 50, 4479-4483 (2002).

15) Lee H. S., J. Agric. Food Chem., 52, 2887-2889 (2004).

16) Saad Z., Hussien R., Saher F., Ahmed Z., J. Zhejiang Univ. Sci. B, 7, 957-962 (2006).

17) Wu H. Q., Li J., He Z. D., Liu Z. G., Parasitology, 137, 975-983 (2010).

18) China Pharmacopoeia Committee, "Pharmacopoeia of People's Republic of China," Chemical Industry Press, Beijing, 2005.
19) Zeng Q. Q., Cai Y. W., Yan Z., Wang X. G., Wang Y. S., J. Pla. Res. Envir., 15, 21-25 (2006).

20) Zeng Q. Q., Yan Z., Cai Y. W., Mo X. L., Wang Y. S., Nat. Pro. Res. Dev., 18, 541-544 (2006).

21) Yang D. P., Chaumont J. P., Millet J., J. Micro., 18, 1-5 (1998).

22) Liu A. R., Yu Z. Y., Lu L. L., Sui Z. Y., Zhongguo Ji Sheng Chong Xue Yu Ji Sheng Chong Bing Za Zhi, 18, 76-78 (2000).

23) Mo X. L., Yan Z., Wang Y. S., Wang X. G., Chin. Her. Med., 27, 805-807 (2004).

24) Kong G. X., Chin. J. Hos. Phar., 6, 32-33 (1986).

25) Abbott W. S., J. Am. Mosq. Control Assoc., 3, 302-303 (1987).

26) Guan L., Quan L. H., Xu L. Z., Cong P. Z., Chin. J. Chin. Mat. Med., 19, 355-357 (1994).

27) Luo J., Feng Y., Guo X., Li X., Zhong Yao Cai, 22, 25-28 (1999).

28) Wang J. H., Fu H., Lishizhen Med. Mat. Med. Res., 11, 579-580 (2000).

29) Zhang G. W., Lan W. J., Su J. Y., Zeng L. M., Yang D. P., Wang F. S., Chin. Tradit. Herbal Drugs, 33, 210-212 (2002).

30) Bender M., Thomas R. J., Journal of the American Chemical Society, 83 (1961).

31) Shusherina N. P., Levina R. Y., Russ. Chem. Rev., 37, 198-208 (1968).

32) Pocker Y., Green E., J. Am. Chem. Soc., 95, 113-119 (1973)

33) Bezmenova T., Slutskii V., Chem. Heterocycl. Compd., 23, $1293-$ 1296 (1987).

34) Smith M. B., March J., "March's Advanced Organic Chemistry: Reactions, Mechanisms, and Structure," Wiley-Interscience, New York, 2001. 